\title{
THE INFLUENCE OF IRRIGATION ON THE GROWTH OF PAULOWNIA TREES AT THE FIRST YEAR OF CULTIVATION IN A LIGHT SOIL.
}

\begin{abstract}
Wiesław PTACH, Faculty of Civil and Environmental Engineering, Warsaw University of Life Sciences - SGGW, Nowoursynowska str. 166, 02-776 Warsaw, Poland, wieslaw_ptach@sggw.pl (corresponding author)

Ariel LANGOWSKI, Faculty of Agriculture and Biotechnology, UTP University of Science and Technology, Bernardyńska str. 6, 85-029 Bydgoszcz, Poland, ariellangowski@ gmail.com

Roman ROLBIECKI, Faculty of Agriculture and Biotechnology, UTP University of Science and Technology, Bernardyńska str. 6, 85-029 Bydgoszcz, Poland, rolbr@utp.edu.pl

Stanisław ROLBIECKI, Faculty of Agriculture and Biotechnology, UTP University of Science and Technology, Bernardyńska str. 6, 85-029 Bydgoszcz, Poland, rolbs@utp.edu.pl

Barbara JAGOSZ, Faculty of Biotechnology and Horticulture, University of Agriculture in Krakow, 29 Listopada av.29, 31-425 Kraków, Poland, b.jagosz@ogr.ur.krakow.pl

Vilda GRYBAUSKIENE, Faculty of Water and Land Management, Aleksandras Stulginskis University in Kaunas, Universiteto str. 10-227 LT-53361 Kaunas, Lithuania, vilda.grybauskiene@asu.lt

Mateusz KOKOSZEWSKI, Faculty of Agriculture and Biotechnology, UTP University of Science and Technology, Bernardyńska str. 6, 85-029 Bydgoszcz, Poland, mateuszkokoszewski@wp.pl

The field experiment was carried out in 2016 on sandy soil in the forest nursery Białe-Błota (Bydgoszcz Forest Division, Poland). The effect of sprinkler irrigation on the growth Paulownia Shan Tong trees was investigated. The experiment was established as one factorial. The variability factor was the irrigation: S-sprinkler irrigation and C- without irrigation (control). The process included the controls of growth parameters: tree height, trunk diameter, number and surface of leaves. It was found that the sprinkled seedlings of Paulownia Shan Tong were significantly higher than those growing in the non-irrigated plots. The sprinkler irrigation applied in the experiment resulted in an increase in the number of leaves of the Paulownia and their surface area, which resulted in an increase in biomass yield. By analysing the results of the study on trunk diameter, leaf number and surface, it may be stated that irrigation watering significantly influenced the tested parameters. Irrigation significantly increased the height of Paulownia trees. The positive effect of the usage of sprinkler irrigation may indicate the possibility of effective application of this method in the field cultivation of Paulownia Shan Tong.
\end{abstract}

Keywords: Paulownia, Growth, Forest nursery, Sprinkler irrigation, Light soil.

\section{INTRODUCTION}

Paulownia species are indigenous to China and have been used as an agroforestry tree for over 2600 years due to their many positive attributes and multifaceted uses. The genus was named in honor of Queen Anna Pavlovna from The Netherlands (1795-1865), the daughter of Tsar Paul I of Russia (Woods, 2008). It is also called the Chinese Empress tree, the Princess tree or the Kiri tree. Zhao-Hua et al. (1986) states that there are nine major species in the Paulownia genus which are all native to East Asia. Paulownia, in particular P. tomentosa, has been planted as an ornamental tree in NW Europe since the early 1800`s but has not been considered as a possible commercial species in the region until the last few years. The results of studies, based on data gathered from existing sites, presented by Jensen (2016), indicates that Paulownia species and the hybrids could grow successfully as a commercial agroforestry crop in north-western Europe. Paulownia can be propagated by seeds, roots or stem cuttings. There are many commercial hybrids, available for sale from plant nurseries, depending on the climate and commonly available in Europe. Wenhua (2001) noted that some excellent Paulownia hybrids have been bred in recent years, for example Paulownia fortunei x Paulownia tomentosa that provide up to $30 \%$ higher timber volume than Paulownia elongata while still being suitable for intercropping.

Paulownia trees are characterized by a wide range of uses. Whether the goals of a Paulownia planting are site reclamation, animal waste utilization, rapid biomass production, or pulpwood for paper production (Olson and Carpenter, 1985). Paulownia is an appropriate tree for intensive management in hardwood plantations with short rotation because of its rapid growth, ability to stump sprout and the wide variety uses for its wood and fiber. Paulownia does not require

Copyright (C) 2017 The Authors. Published by Aleksandras Stulginskis University. This is an open-access article distributed under the terms of the Creative Commons Attribution License (CC-BY 4.0), which permits unrestricted use, distribution, and reproduction in any medium, provided the original author and source are credited. 
replanting after harvest, because it regenerates from stump sprouts. Paulownia wood is used for a multitude of products because it is attractive, strong, lightweight, quick-drying, versatile and has good resonance qualities. The wood is easily worked and will not split or crack when spikes are driven into it or with rapid drying (Clatterbuck, Hodges, 2004). Due to the high price of balsa, Paulownia wood is also used as an element of composite construction material, which can replace balsa wood in sandwich structures applied among ships, aircrafts, automobiles or wind energy systems (Li, Weiqing, Hai, Ding, 2010). It has been recorded that an 8-10 year old Paulownia tree can produce $100 \mathrm{~kg}$ of fresh leaves per year (Wang and Shogren, 1992). The leaves and flowers of Paulownia are rich in nitrogen and other nutrients which could serve as good natural fertiliser (Wang and Shogren, 1992). Furthermore, the leaves of Paulownia have a high nutritive content suitable for ruminants (Bodnár et al., 2014) and can be ensiled as a fodder crop. The leaves are also fed to pigs and rabbits (Wang and Shogren, 1992; Zhao-Hua et al, 1986).

The plant analyzed in this paper is a hybrid of Paulownia called Shan Tong, characterized by very rapid growth (trunk diameter, after 8-10 years, reaches $50 \mathrm{~cm}$ ), resistance to low temperatures (to $-27^{\circ} \mathrm{C}$ ), strong root system and large leaves (up to $60 \mathrm{~cm}$ wide), light and easy to processing wood (40\% lighter than pine) (Biomass Energy Project. 2017). In Poland, Paulownia Shan Tong is a new species, introduced due to the potential benefits of growing for the paper, furniture and biomass production. Unfortunately there is a lack of reliable publications on Paulownia behavior and cultivation in Poland. The experiments on the influence of chosen saccharides on the growth and development of the in vitro shoot cultures of Paulownia tomentosa were made by Litwińczuk W. and Bochnia E. (2012). The researches on examine usefulness of Paulownia tomentosa for cultivation for biomass in south-eastern Poland were made by Jacek B. and Litwińczuk W. (2016). The results of their researches show that Paulownia plantations can be recommended in sandy soils under the condition of provision of an irrigation system. Sprinkler irrigations systematically deliver of optimal doses of water to plants and it is characterized by a high water utilization rate (Kaczmarczyk, Nowak, 2006). The effect of using this type of irrigation is to provide conditions for the production of valuable seedlings (Sobczak, 1999). The positive effects of the microirrigation and other revitalization treatments on the development of plants produced in the forest nurseries in the region of Bydgoszcz were already observed in the case of species, such as Scots pine (Klimek et al., 2008), white birch (Klimek et al., 2009), European larch (Klimek et al., 2011) and little leaf linden (Klimek et al., 2013).

The purpose of this study was to determine how sprinkler irrigation influences the growth parameters of the Paulownia Shang Tong in the first year of growing on light soil in a low rainfall area. The paper presents the preliminary results of these studies.

\section{MATERIALS AND METHODS}

The field researches were conducted during 2016 vegetation season at the forest nursery "Białe Błota" (Bydgoszcz Forest Division, Poland). Experiment was run on a brown podzolic soil formed from a loose sandy soil. Two years old seedlings (from rootstock) were planted in two rows with spacing of 5 meters in row and 3 meters between rows. The experiment was designed as one-factorial trial. One factor was considered: irrigation (sprinkler irrigation and control without irrigation). During the experiment the changes of the height, the diameter of the trunk and the number of leaves were observed. Also the surfaces for representative leafs (from second node of the plant) were measured and compared.

Meteorological conditions. The results of precipitation and air temperature measurements were obtained from meteorological station located in Mochełek, owned to Department of Land Reclamation and Agrometeorology, University of Science and Technology in Bydgoszcz (Poland). The average air temperature during 2016 vegetation season was 16.3 ${ }^{\circ} \mathrm{C}$ and for 2017 vegetation season $15.7^{\circ} \mathrm{C}$. Temperatures higher than mean values for 1981-2010 were observed in May, June and September of 2016. The temperature in July and August 2016 was lower than the value from many years. Total rainfall measured during vegetation season of 2016 was $358 \mathrm{~mm}$ and was higher than the average value from many years by $27.6 \%(77.5 \mathrm{~mm})$. In the months of May to July, there was a higher rainfall than the average for many years (19812010). Particularly high rainfall was recorded in July in which the precipitation amounted to $133.8 \mathrm{~mm}(91.7 \% \mathrm{more}$ than in many years). In August and September there was a decrease in precipitation. The particularly precipitation in September was $57.8 \%$ lower than the long-term average.

Table 1. Rainfall and air temperature in the vegetation period 2016 in the vicinity of Bydgoszcz.

\begin{tabular}{|c|c|c|c|c|c|c|}
\hline \multirow{2}{*}{ Years } & \multicolumn{6}{|c|}{ Month } \\
\hline & $\mathrm{V}$ & VI & VII & VIII & IX & V-IX \\
\hline \multicolumn{7}{|c|}{ Rainfall [mm] } \\
\hline Mean values for $1981-2010$ & 49.3 & 52.8 & 69.8 & 62.6 & 46.0 & 280.5 \\
\hline Values for vegetation period 2016 & 51.4 & 98.1 & 133.8 & 55.3 & 19.4 & 358.0 \\
\hline $\begin{array}{l}\text { Deviation from long-term average } \\
{[\%]}\end{array}$ & +4.3 & +73.9 & +91.7 & -11.7 & -57.8 & +27.6 \\
\hline \multicolumn{7}{|c|}{ Air temperature $\left[{ }^{\circ} \mathrm{C}\right]$} \\
\hline Mean values for $1981-2010$ & 13.1 & 16.0 & 18.5 & 17.9 & 13.2 & 15.7 \\
\hline Values for vegetation period 2016 & 14.7 & 17.7 & 18.3 & 16.4 & 14.3 & 16.3 \\
\hline Deviation from long-term average [\%] & +12.2 & +10.6 & -1.1 & -8.4 & +8.3 & +3.8 \\
\hline
\end{tabular}

Irrigation. The irrigation was done using solid-set hand-line irrigation system with overhead impact sprinklers mounted on risers. The irrigation radius of sprinklers was $\mathrm{R}=10 \mathrm{~m}$. The water output was $2.5 \mathrm{~m}^{3} / \mathrm{h}$. Water for irrigation 
was taken from the retention reservoir located in the forest nursery. Natural precipitation was measured using a Hellmann rain gauge and was $358 \mathrm{~mm}$ in this period. Sprinkling irrigation was started 14 days after tree seedlings planting (1 May) and ended on 30 September. During the first 14 days after planting, seedlings did not form leaves. Irrigation was used to supplement natural rainfall. Sprinkler irrigation was realized in accordance with the recommendations for forest nurseries on open areas. Terms of irrigation and irrigation doses were established according to "Directives for irrigation of forest nurseries on open areas" (Pierzgalski E. et al. 2002). The first irrigation was performed 14 days after seedlings planting. The term of irrigation was dependent on current precipitation and its main objective was the compensation of water deficit in a particular stage of plant growth (Tab.1). Irrigation in July 2016, when high monthly rainfall was observed was realized only in the period without precipitation. The irrigation dose $(20 \mathrm{~mm})$ was applied in the first decade of the month. In this decade, only $29 \mathrm{~mm}$ (approximately $20 \%$ ) of the monthly sum $(133.8 \mathrm{~mm}$ ) was recorded. In the other two decades of July, there was more rainfall and irrigation was not necessary. The total irrigation dose applied from 1 May to 30 September was $170 \mathrm{~mm}$.

Table 2. Dependence of the irrigation dose from rainfall during in the vegetation period 2016.

\begin{tabular}{|l|c|c|c|c|c|c|}
\hline & V & VI & VII & VIII & IX & $\sum$ \\
\hline Rainfall $[\mathrm{mm}]$ & 51.4 & 98.1 & 133.8 & 55.3 & 19.4 & 358 \\
\hline Irrigation dose $[\mathrm{mm}]$ & 30 & 30 & 20 & 40 & 50 & 170 \\
\hline Sum Total $[\mathrm{mm}]$ & 81.4 & 128.1 & 153.8 & 95.3 & 69.4 & 528 \\
\hline
\end{tabular}

The increase of the height of Paulownia seedlings, the trunk diameter (measured at the height of $5 \mathrm{~cm}$ ), the number of leaves and surface of representative leaf for two variants of experiment were determined at 30 day intervals.

\section{RESULTS I DISSCUSSION}

Sprinkler irrigation significantly affected the height of Shan Tong Paulownia (Fig.1). The difference in plant height was observed throughout all months of the vegetation season (Photo1,2). The biggest difference between plants height in the variants of experiment was observed in September. It was equal to 58.3 centimeters (78.5\%). During the all moths of the vegetation season, irrigated Paulownia gave an averages of $68.2 \%$ more growth than non-irrigated trees. The fastest monthly growth increase of irrigated Paulownia $(57.3 \mathrm{~cm}$ ) was observed between June and July. For non-irrigated (control) variant, dynamic growth was observed also between June and July. Monthly growth during this period was equal to $34 \mathrm{~cm}$.

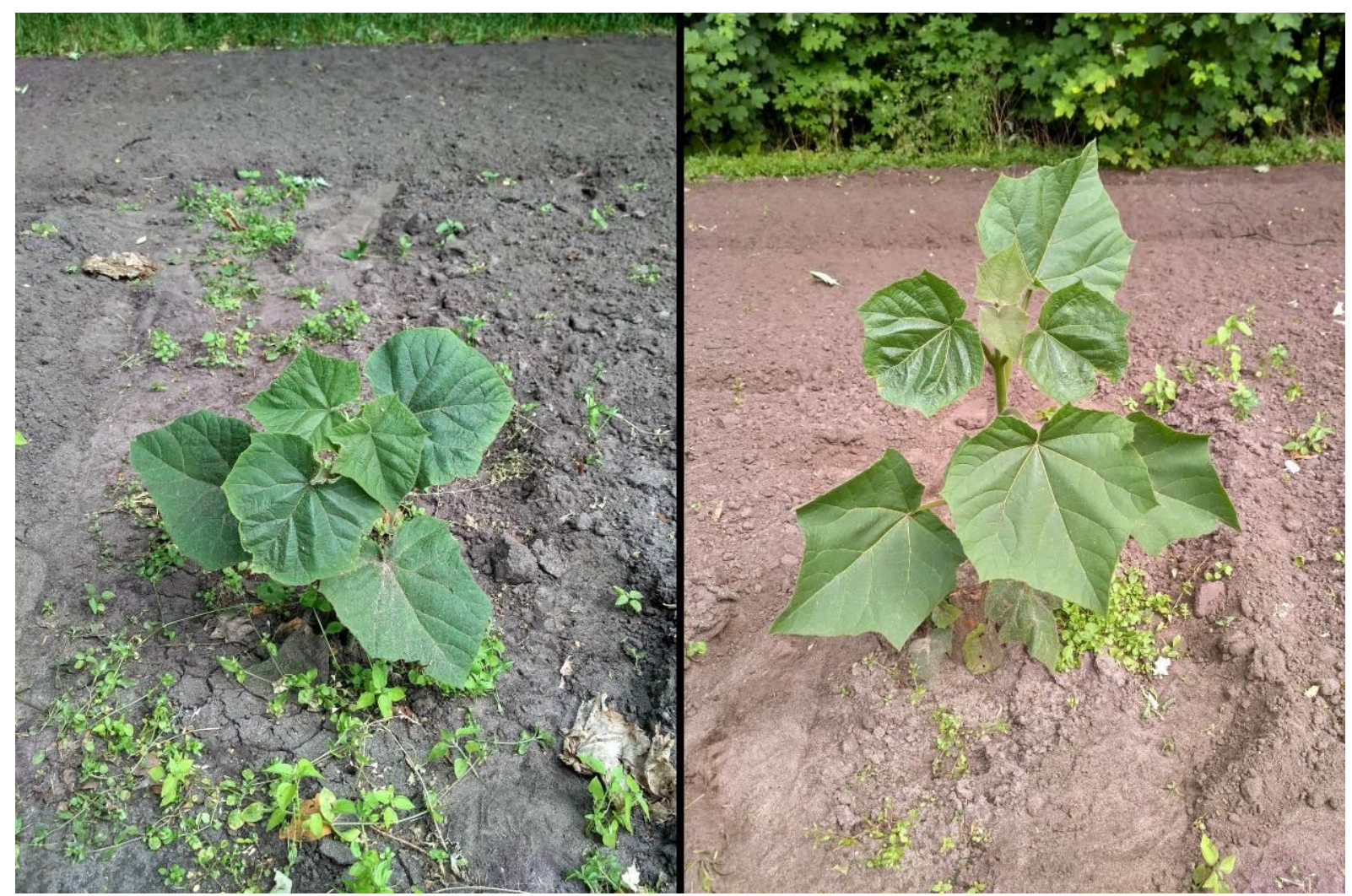

Photo 1. Comparison of Paulownia growth for unirrigated (left ) and irrigated (right) trees in June 2016. 


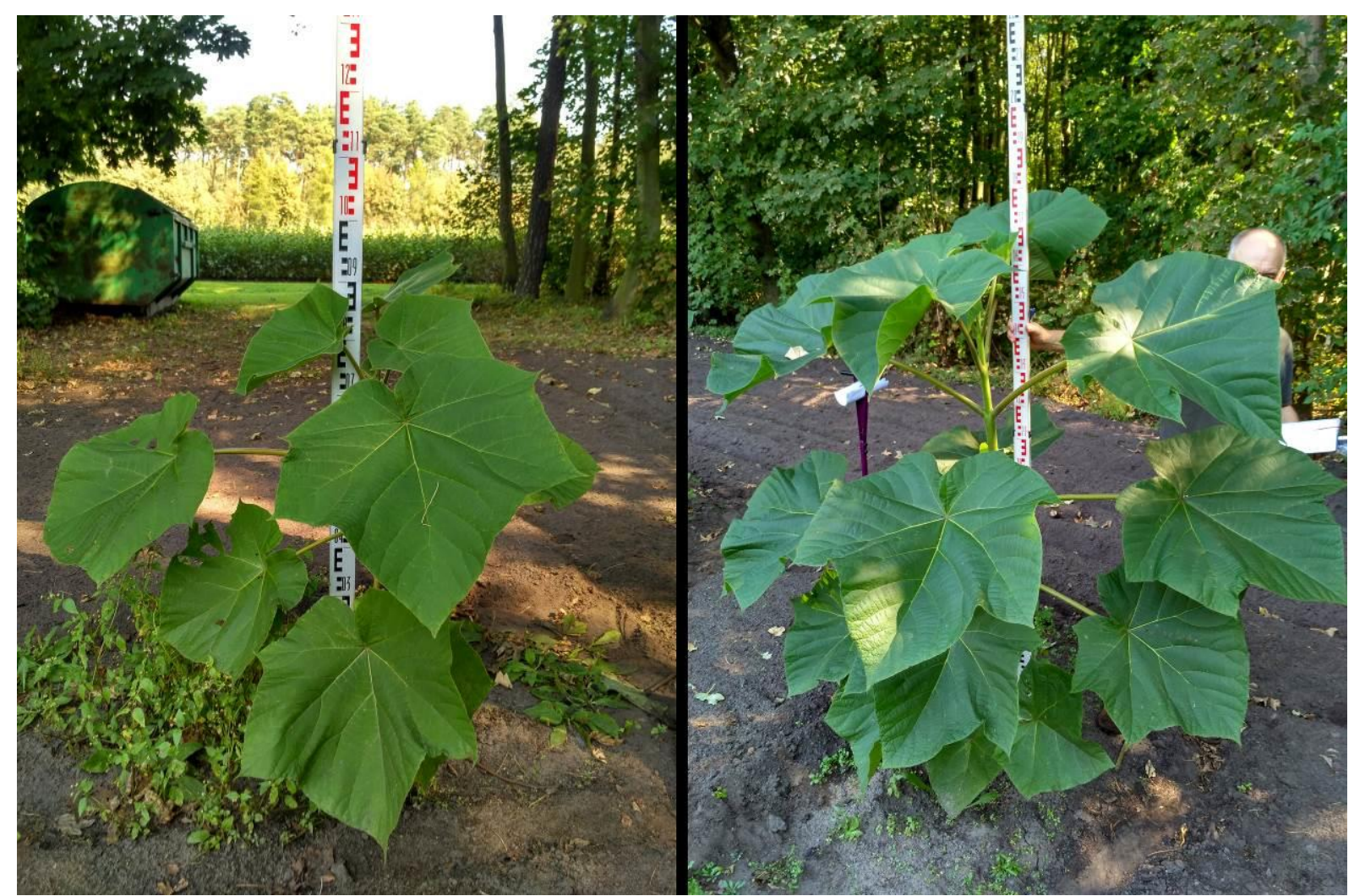

Photo 2. Comparison of Paulownia growth for unirrigated (left) and irrigated (right) trees in September 2016.

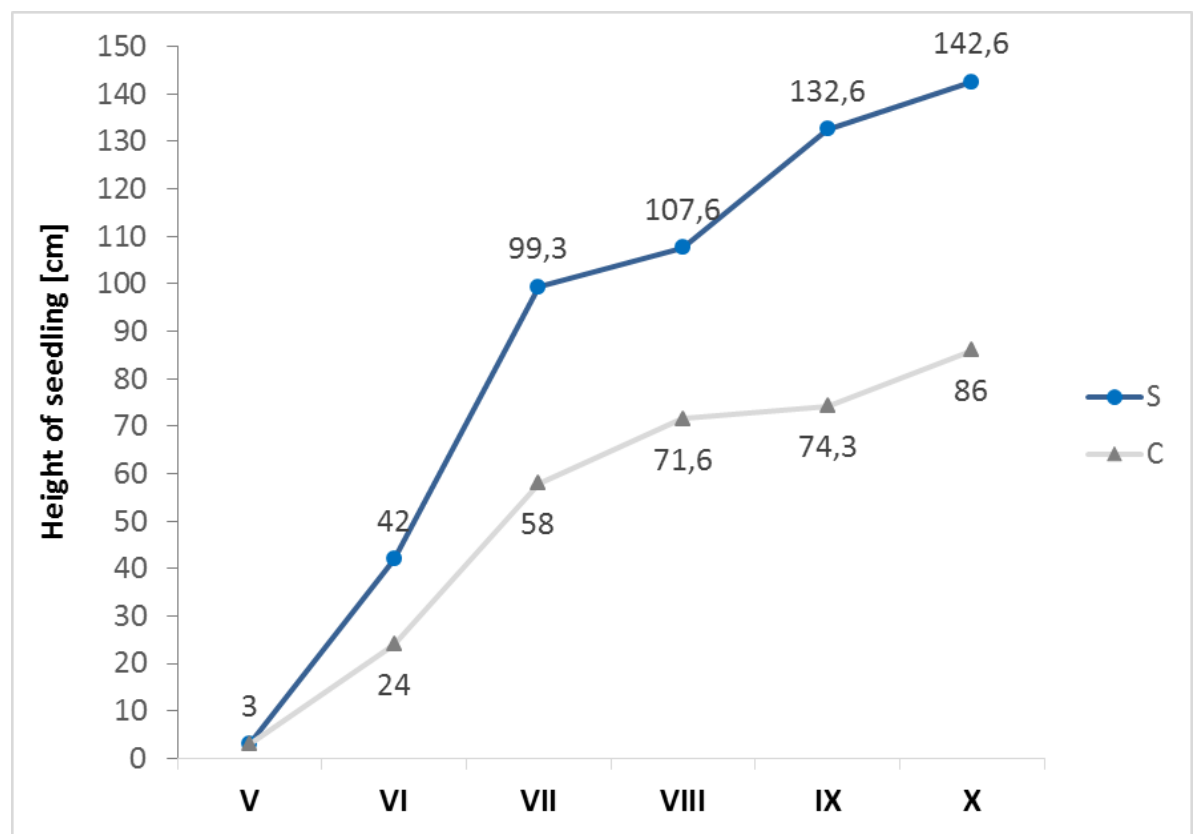

Figure 1. The changes of height of seedlings for irrigated (S) and unirrigated (C) Paulownia trees observed during the 2016 vegetation season.

Analyzing the results of the study of the trunk diameter, leaf number and surface, it can be stated that irrigation watering had a significant influence on the tested parameters. The monthly average increase of trunk diameter for the control variant was equal to $5.2 \mathrm{~mm}$, while for the irrigated Paulownia 7,9 mm (52\% more). At the end of the vegetation season the irrigated plants achieved an average of $39.7 \mathrm{~mm}$ of the trunk diameter (Fig. 2) while the non-irrigated ones only $25.9 \mathrm{~mm}$. The difference in trunk diameter growth was 53.3\%. For Paulownia growing for commercial harvesting, the rate of growth of the trunk diameter will have a significant influence on the early harvesting of the crop and consequently on the yield of the crop. Analyzing the influence of sprinkling irrigation on the increase of leaf numbers and thus the increase in leaf mass, two stages of growth can be observed. During the first part of vegetation season, from May to July, despite the differences in plant height, the numbers of leaves in both analyzed variants were similar (two more leaves were observed in irrigated trees - Fig.3). In the second part of vegetation period (from July to October), greater difference in leaf number was observed. At the end of the growing season, the difference in the leaves number between 
the two variants was 8 leaves per tree (44.4\%). During the experiment (in June and September), the leaves surfaces of the Shan Tong Paulownia were measured and compared (Tab. 3). There was a significant difference in leaf area in each month for both variants of the experiment. The leafs' area of the of irrigated Paulownia, measured in June, was larger than the one of non-irrigated tree, and the difference between them was equal to $233.7 \mathrm{~cm}^{2}(266.5 \%$ more). The similar difference in size of leaf areas for both variants of the experiment was observed in September. The difference in measured leaf size of irrigated and non-irrigated Paulownia was $1346.3 \mathrm{~cm}^{2}(243.4 \%)$. Comparing the results of leaf area measurements, made in August and September, it can be stated that already in August the maximum leaf area was obtained for both variants of the experiment. Despite the continued irrigation, the leaf area is maintained at a similar level with the downward trend of the area for the new leaves of the Paulownia.

Table 3. The comparison of the surfaces of representative leafs at selected periods of the 2016 vegetation season.

\begin{tabular}{|c|c|c|}
\hline \multicolumn{3}{|c|}{ Leaf surface $\left[\mathrm{cm}^{2}\right]$} \\
\hline Month & C- Control & D- Irrigated \\
\hline VI & 87.7 & 321.4 \\
\hline VIII & 683.2 & 1988.3 \\
\hline IX & 553.0 & 1899.3 \\
\hline
\end{tabular}

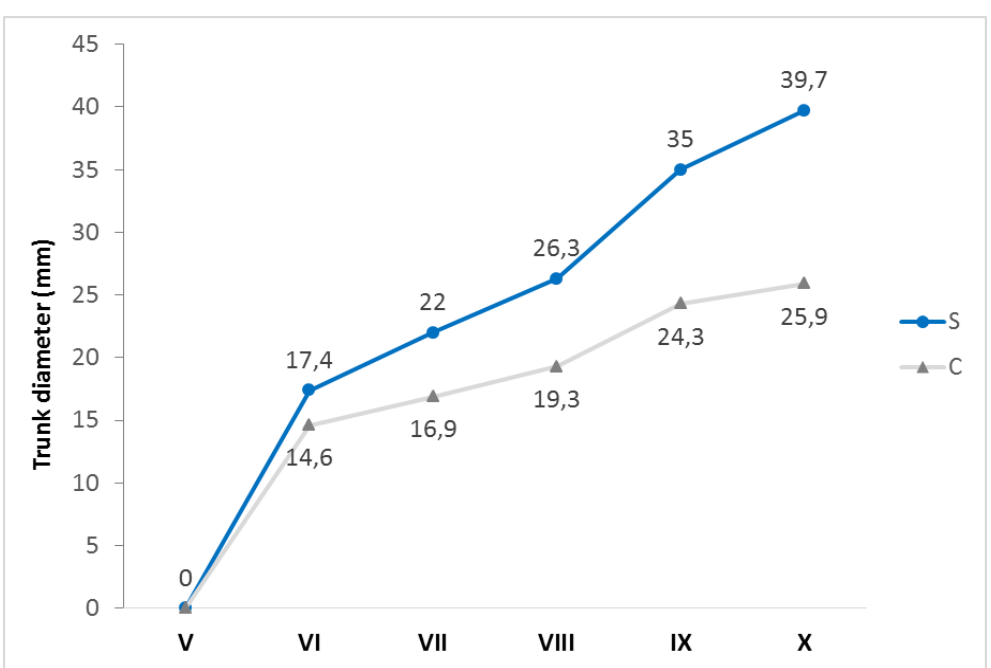

Figure 2. Trunk diameter changes for irrigated (S) and unirrigated (C) Paulownia trees observed during the 2016 vegetation season.

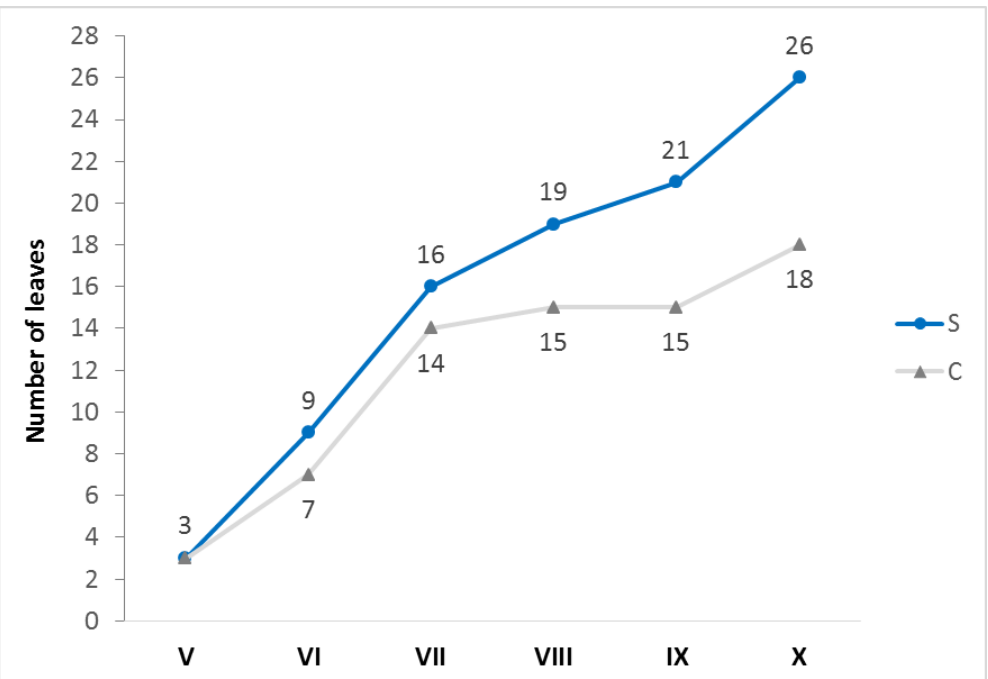

Figure 3. The changes of number of leaves for unirrigated (C) and irrigated (S) Paulownia trees observed during the 2016 vegetation season.

The results of experiment are similar to the results presented by Mirkala J.E. and Rad S.R. (2015) who have studied influence of irrigation on Paulownia growth. They noted, that more than $80 \%$ of growth took place in the first 3 months of growing.

\section{CONCLUSIONS}

1. Paulownia trees, cultivated in Poland, may become to be the valuable source of timber and biomass. 
2. By analysing the results of the study on trunk diameter leaf number and surface, it may be stated that irrigation watering significantly influenced the tested parameters. Irrigation significantly increased the height of Paulownia seedlings. The average difference between the variants (irrigated and control) at the end of the growing season was $65.5 \%$ on average. The difference in trunk diameter growth was $53.3 \%$.

3. The sprinkler irrigation applied in the experiment resulted in an increase in the number of leaves of the Paulownia and their surface area, which resulted in an increase in biomass yield. The difference in measured leaf size of irrigated and non-irrigated Paulownia was $1346.3 \mathrm{~cm}^{2}(243.4 \%)$.

4. It is necessary to repeat the experiment to accurately determine the technology of irrigation.

\section{ACKNOWLEDGEMENTS}

Acknowledgements are due to the Białe Błota Forest Nursery Staff for providing the necessary support during field researches and data collection.

\section{REFERENCES}

1. Biomas Energy Project. Available at: http://www.bep-sa.pl/aktualnosci/paulownia__zielona_sila_biznesu.html (Accessed on 02.03.2017)

2. Bodnár, A., Pajor, F., Steier, J., Kispál, T., Póti, P. 2014. Nutritive value of paulownia (Paulownia spp.) hybrid tree leaves. Hungarian Agricultural Research, Vol. 23 No. 4 pp. 27-32.

3. Clatterbuck, W.K., Hodges, D.G. 2004. Tree Crops for Marginal Farmland-Paulownia. PB1465. The University of Tennessee Agricultural Extension Service. Mansuscript. pp. 33.

4. Jacek, B., Litwińczuk, W. 2016. The selected biomass properties of Paulownia tomentosa strains cultivated for energy purposes in the first two years of vegetation. Annals of Warsaw University of Life Sciences - SGGW Agriculture No 68 (Agricultural and Forest Engineering). pp. 61-66.

5. Jensen, J.B. 2016. An investigation into the suitability of Paulownia as an agroforestry species for UK \& NW European farming systems. Department of Agriculture \& Business Management. Scotland`s Rural College. Manuscript. pp.206.

6. Kaczmarczyk, S., Nowak, L. 2006. Plants irrigation, State agricultural and forestry publishing house, Poznań (in Polish).

7. Klimek, A., Rolbiecki, S., Rolbiecki, R., Hilszczańska, D., Malczyk, P. 2008. Impact of chosen bare root nursery practices in Scots pine seedling quality and soil mites (Acari). Polish Journal of Environmental Studies, Vol. 17, Iss. 2, pp. $247-255$.

8. Klimek, A., Rolbiecki, S., Rolbiecki, R., Malczyk, P. 2009. Impact of chosen bare root nursery practices on white birch seedling quality and soil mites (Acari). Polish Journal of Environmental Studies, Vol. 18, Iss. 6, pp. 1013-1020.

9. Klimek, A., Rolbiecki, S., Rolbiecki, R., Hilszczańska, D., Malczyk, P. 2011. Effects of organic fertilization and mulching under micro-sprinkler irrigation on growth and mycorrhizal colonization of European larch seedlings, and occurrence of soil mites. Polish Journal of Environmental Studies, Vol. 5, Iss. 20, pp. 1211-1219.

10. Klimek, A., Rolbiecki, S., Rolbiecki, R., Długosz, J., Musiał, M. 2013. The use of compost from sewage sludge and forest ectohumus for enrichment of soils in the nursery cultivation of littleleaf linden (Tilia cordata Mill.). Annual Set the Environment Protection, Vol. 15, pp. 2811-2828.

11. Li W., Weiqing L., Hai F., Ding Z. 2010. Interlaminar Behavior of Paulownia Wood Sandwich Composites with Grooves. Proceedings of the 5th International Conference on FRP Composites in Civil Engineering. September 27-29, 2010, Beijing, China. p. 123-126.

12. Litwińczuk, W., Bochnia, E. 2012. Development of Royal Paulownia (Paulownia Tomentosa steud.) in vitro shoot cultures under the influence of different saccharides. Acta Scientiarum Polonorum., Hortorum Cultus, Vol. 11, Iss. 2, pp. 3-13.

13. Olson, J., Carpenter H. 2008. Specific gravity, fiber length and extractive content of young Paulownia. Wood and Fiber Science, Vol. 17 (4), pp. 428-438.

14. Pierzgalski E., Tyszka J., Boczoń A., Wiśniewski S., Jeznach J., Żakowicz S. 2002. Directives for irrigation of forest nurseries on open areas. General Directoriate of The State Forests, Warsaw (in Polish).

15. Rad J.E., Mirkala S.R. 2015. Irrigation effects on diameter growth of 2-year old Paulownia tomentosa samplings. Journal of Forests Researches, Vol. 26 (1), pp. 153-157.https://doi.org/10.1007/s11676-014-0007-7

16. Sobczak R. 1991. Forest and ornamental forest nurseries. World Publishing House, Warsaw [In Polish].

17. Wang Q., Shogren J.F. 1992. Characteristics of the crop-paulownia system in China. Agriculture, Ecosystems and Environment, Vol. 39, pp 45-152. https://doi.org/10.1016/0167-8809(92)90050-L

18. Wenhua L. 2001. Agro-ecological Farming Systems in China. Man and the Biosphere Series, Vol. 26. The Parthenon Publishing Group Limited, Casterton Hall.

19. Woods V.B. 2008. Paulownia as a novel biomass crop for Northern Ireland? A review of current knowledge. Occasional Publication No 7. Agri-Food and Biosciences Institute. Hillsborough. Northern Ireland. pp. 56.

20. Zhao-Hua, Z., Ching-Ju, C., Xin-Yu, L., Yao Gao, X. 1986. Paulownia in China: Cultivation and Utilisation. Asian Network for Biological Sciences and International Development Research Centre. Available at: https://paulowniamp.files.wordpress.com/2010/05/paulownia-in-china.pdf. (Accessed on 02.03.2017). 